\title{
Pandemic as a prerequisite of discrimination of the senior citizens
}

\author{
Nadezhda Nikolaevna Tarusina ${ }^{11}$, Aleksandr Vladimirovich Sokolov ${ }^{2}$, and Elena \\ Aleksandrovna Isaeva $^{1}$ \\ ${ }^{1}$ P. G. Demidov Yaroslavl State University, Department of Social and Family Law, Yaroslavl, Russia \\ ${ }^{2}$ P.G. Demidov Yaroslavl State University, Department of Social-Political Theories, Yaroslavl, Russia
}

\begin{abstract}
The objective of the research is to reveal and comprehend the peculiarities of the status (complex of rights of their restrictions) of the citizens in the conditions of pandemic COrona VIrus Disease-19, in particular, of the new category of minorities - people at the age of 65+ years old. The methodological base of the research is the universal, general scientific and specific scientific cognitive methods used by the legal science in the object-subject scope of cognition of the general theory of law. The process of research was focused on the comparativistics, and the historical and legal, comparative and legal, technical and other special methods of scientific cognition were applied. To estimate the situation the empiric data of the three sociological researches when questioning the dwellers of Yaroslavl Region were used. The results of the research of the comfort level of the senior citizens in the specified conditions obtained during the analysis of the legislation, and its practical application and the data of sociological researches became the conclusions that the prohibited activities do not only protect from risks but also create the new ones intellectual, psychic and physical moments. The authors believe that as the emergency situations cannot be settled by the current pandemic, the state has to correct its regulatory and legal and managerial positions taking into account the own experience and recommendations of the specialists, including those regarding the status of a new group of minorities that is the citizens at the age of $65+$ years old. The novelty of the research was stipulated by the formulated recommendations to form the optimal regulatory and legal limits of the positive discrimination of the mentioned category of citizens.
\end{abstract}

Keywords: pandemic, restrictions, prohibitions, minorities, discrimination, senior citizens

\section{Introduction}

The history of appearance of the various minorities is uncommon and quite informative, and the political, economic, ethical and legal characteristics of their actual existence and the breakthrough of the latter into the freedom space and autonomy are very relevant and correspondingly, are the constant object of the theoretical and practical research. Despite

${ }^{1}$ Corresponding author: nant@uniyar.ac.ru 
the mentioned continuity, the definition of this notion has not reached the level of doctrinal agreements. The main problem when solving this question is the abnormal variety of applicants. The doctrine distinguishes qualitative and quantitative characteristics of the specified groups. It is quite evident that it is just the starting point that inevitably will turn into the marks of omission, as the social groups of minorities are much more diverse (according to the criteria of gender, age, employment, political orientation, etc.) [1]. The concerns are expressed that the size of the group is not an obligatory criterion in some cases, the factor of non-dominance is more important [2].

The phenomenon of minorities is stipulated by the diversity of the subjects, factors and circumstance in time and space of human being. If the political and legal systems are oriented to the preservation of the identity of some groups of population and their development, their special legal statuses shall be formed on the base of the overcoming of the discriminating positions, provision of advantages (within the framework of the "positive discrimination") and in some cases the introduction of restrictions according to the necessity. The pandemic 2020 became the catalyst that prerequisite the appearance of the new type of minorities - a group of senior citizens of $65+$ years old, for whom the Russian authorities together with the general restrictive measures in the emergency situation introduced the additional prohibitions - first of all in the form of self-imposed isolation. These decisions were explained by the care about citizens from the age risk group. It should also be noticed that the elements of discrimination of the senior citizens existed before, first of all in the social security and labor-legal fields, and in the sociological field in the context of the "gerontological ageism". In the period of pandemic the legal and actual restrictions were intensified and extended.

In this regard the objective of our research is comprehension of the peculiarities of the status (complex of rights of their restrictions) of the citizens in the conditions of pandemic of COVID-19, in particular, of the new category of minorities - people at the age of 65+ years old. The research is aimed to develop the recommendations for formation of the optimal regulatory and legal frames of the positive discrimination of the specified category.

\section{Methods}

The methodological base of the research is the universal, general scientific and specific scientific cognitive methods used by the legal science in the object-subject scope of cognition of the general theory of law. The process of research was focused on the comparativistics, and the historical and legal, comparative and legal, technical and other special methods of scientific cognition were applied. To estimate the situation the empiric data of the three sociological researches were used (including one research performed involving the authors of the article, the questioning the dwellers of Yaroslavl Region representative sample of 648 people).

\section{Results and discussion}

In the world practices, including the Russian social and legal ones the fixation of some groups of minorities, as a rule, means the two opposite positions: statement of their particular infringement (discrimination) and provision of the additional possibilities: not only for aligning with the corresponding dominants but sometimes for the advance full development. In the doctrine such practices are often called "positive discrimination", but more often they are called - "differentiation" [3]. As a variant of the practice of status aligning the complex of actions cannot be excluded: decreasing (but not exclusion!) of the dominating elements when saving (increasing) of the encouraging elements. The bright 
example of such type is the decisions of keeping or correcting of some advantages for women - in the family and legal sphere [4], the changes of their labor and legal status (lifting of some bans for professions [5] and enlargement of the social security benefits due to the pregnancy and birth of a child). "Minorities" and/or "discriminated groups" [6] made a long and rather difficult way to the optimization of their possibilities, including the law field.

However, as far as is known, life is hardly predictable: new circumstances appear and new minorities are born. It is such circumstance, moreover of the emergency character, was the pandemic of COVID-19 [7], that caused the break of current links in the regulatory and legal chain and formation of non-standards links (at the initial stages they are mostly spontaneous and hectic). And it is this pandemic that showed to the world and first of all to Russia the specific category of minorities - senior citizens of $65+$ years old. On one side, it should not go unmentioned that the history of status of the senior citizens is quite contradictory, in times and territories (from their active and passive slaughter as weak and unnecessary for the warriors society and/or survival society up to the cult of the elderly), on the other side, in the moment this general social and legal status is also contradictory although it has some other accents in the content. Despite the fact that the senior citizens still belong to the quantitative minority (in the Russian Federation the citizens of 65 years old and older are $15.47 \%$ of the total population (as on January 01,2020 , women $-66.69 \%$, men $-33.31 \%$ ), their number is drastically increasing and this intensifies the tension in the spheres of social security, healthcare, etc. The idea of "gerontological agism" appears in the sociology [8], that is a complex of discriminating practices and affirmations in respect to the senior citizens [9] and in the social security blocks of the Russian jurisprudence they are also added with the term "age of survival" and this does not make it look better. In the practice of application of the labor legislation the cases of age discrimination are clearly seen [10]. (And this is despite the fact that among the political leaders of many countries and in the sphere of high art the senior citizens make a rather big group).

In 2020 (and in 2021) the problems related to the realization of the right to life, the right to manage their lives were extremely relevant (as the components of the first right), including the right to risk the life and also understanding of the obligations to take care about health (that is provided in the Russian legislation in a declarative manner in the Art. 27 of the Federal Law "On fundamental healthcare principles of the citizens of the Russian Federation" or fragmentarily) [11]. These problems were and are in tense interaction with the norm of the Art.55 of the Constitution of the Russian Federation about the assumption of restrictions of rights and freedoms of the citizens in cases provided by the federal legislation. In comparison with the professional risks (objectively inevitable) and even risks related to the other activity (for example, extreme kinds of sport or entertainment activities), due to their mass character and abnormal danger and certainly taking a special place among the objects of legal regulation the pandemic risks require the special technologies for all categories of citizens living or arriving for temporary stay on the territory of the state (restriction of freedom to movement, quarantine measures, partial transfer to the remote working, obligatory use of means of epidemiological protection [12]. We assume that among such citizens the differentiation is inevitable: to the easing of restrictions (for example, for the employees providing the functioning of essential services), and to the intensifying of them. The citizens of $65+$ years old have been referred to the latter category by the Russian state (excluding the above-mentioned categories of the employees).

It should be mentioned that the reason of the introduced (and constantly defining) anti-virus federal and regional legislation was the structure of the high alert mode and not the emergency situation (many lawyers explain it by the mercenariness of the state: the norm of the Art.27 of the Federal Constitutional Law "On emergency situation" provides 
the right of the citizens for compensation of damage and they would like to avoid it in the situation of the significant financial losses for the support of the citizens and economy [13] that created (and continues to create) the condition of the normative uncertainty. However, this uncertainty touches on the group of $65+$ to a far lesser degree because the "arm of the legal prohibitions" was aimed to them as a priority. And it was done by all regions in comparison with the other groups of population. On one side, the grounding of their special "pandemic status" is based upon the objective factors: a significantly higher risk of Coronavirus contamination, its relation to the chronic diseases of the senior citizens, weakened immune system, etc. However, on the other side, all the restrictions imposed on the senior citizens cannot be explained only by the care of the state about them: its base included the considerations about the number of "beds" and the fear of the future death statistics (in the face of the "world community" and its own population), and the hope for the diligence of this age category that was formed in the Soviet period, and also the assumption about rather low level of citizen activism of this age group. This is also confirmed by the results of our research: only $33.7 \%$ of the people older than 60 years old believe in possessing the active citizenship and showing citizen activism. When the lockdown was announced it was supposed that the restrictions for the senior citizens can be mitigated by the possibility to communicate with their dearest, and fill their leisure activities meaningfully by means of the access to the Internet. However, one fact was not taken into account that the major part (51\%) of the senior citizens did not use it [14]. With that the authority also realized that the lockdown mode is extremely harmful for the physical and mental health [15] especially in the specified age range (65+ and older). The sociological researches showed that the quality of life of the senior citizens is significantly influenced by the possibility of their self-fulfillment in everyday practices and on the contrary, the patronage is a negative factor and decreases the efficiency of resistance to the age. Compulsive infantilization (instead of encouragement of the intellectual and physical abilities and voluntary self-restrain) weakens the energy of mind and body and decreases the life potential [16]. Besides the distinct differentiation between the working and not working citizens (pensioners) was not made, the normative exclusions for the category of $65+$ whose labor is necessary for the functioning of the organization (additionally to the staff of the vital services) appeared mainly in the autumn of 2020 and their application certainly was addressed to the managers within the frameworks of the administrative discretion that is in default is subjective.

\section{Conclusion}

The two postulates are offered by the authors as a conclusion.

1. We believe that the senior citizens cannot be taken as "the playthings in a big game", and distinguished into a group discriminated in a special manner [17], the technology of the strict prohibition should not be applied to them, but instead the dispositive method of "soft law": to inform them of the poor statistics and the recommendations of the doctors based upon it, to offer several "carrots" in the form of a sick leaf, material support of those who chose the "self-imposed isolation", system and clear voluntary assistance, high-priority vaccination, free testing for COVID/antibodies, broadcast of the competent TV programs about the risks for this age, etc. (may be in combination with a "stick", for example, cancellation of the travel privilege, etc.). For many senior citizens the support of the anti-virus measures by the Church became quite significant, psychologically and ethically valuable. In comparison with the state the Church, quite obviously, used the persuasion techniques [18].

2. We believe it is evident that the inclusions of the legal and actual discrimination, creation of prerequisites for appearance of the new categories of the minorities should be 
made carefully and in proportion, even in the situations close to the emergencies. We risk to make an assumption that the "pandemic experience" of the government control will not become the base of the awless prohibitions but will be used for the optimization of the technology of transfer of the law normativity into the adequate order of the relations between the state and the person in the period of saving them both.

The reported study was funded by the Russian Foundation for Basic Research, project number 19-011-00268 "Transformation of civic activity in the conditions of the development of information and communication technologies (on the example of the Yaroslavl region)".

\section{References}

1. N. Tarusina, E. Isaeva, Rus. Law J. 4(3), 74-93 (2016)

2. S.A. Dekhkanov, Bul. PFUR Univ. Ser.: Legal Sci. 3, 122-131 (2010)

3. A.M. Lushnikov, M.V. Lushnikova, N.N. Tarusina, Gender v zakone [Gender in the law] (Prospect, Moscow, 2014)

4. N. Tarusina., E. Isaeva, BRICS Law J. 4(4), 65-92 (2017)

5. E.V. Sychenko, Labor Law Rus. Abroad 4, 59-62 (2017)

6. L. Ayalon, Internat. Psychoger. 32(10), 1221-1224 (2020). https://doi.org/10.1017/S1041610220000575

7. A. Rahman, Y. JahanDefining, J. Loss and Trauma 25(8), 631-634 (2020). https://doi.org/10.1080/15325024.2020.1757993

8. R.N. Butler, Gerontologist, 9(4), 243-246 (1969). https://doi.org/10.1093/geront/9.4_part_1.243

9. L.V. Kolpina, E.V. Reutov, Mid. Rus. Bul. Soc. Sci. 14(2), 32-45 (2019). https://doi.org/10.22394/2071-2367-2019-14-2-32-45

10. A.V. Menkenov, Labor Law Rus. Abroad, 3, 54-57 (2019)

11. S.N. Shishkov, S.V. Polubinskaya, State and Law, 10, 81-89 (2020)

12. M.V. Agaltsova, T.V. Imanova, Law, 5, 60-70 (2020)

13. Yu.V. Tay, S.L. Budylin, Law, 4, 128-146 (2020)

14. Kazhdomu vozrastu - svoi seti [Every age has its own networks]. Accessed on: June 30, 2021. [Online]. Available: https://wciom.ru/analytical-reviews/analiticheskii-obzor/kazhdomu-vozrastu-svoi-seti

15. R. Armitage, L.B. Nellums, Lancet Pub. Health 5(5), e256 (2020). https://doi.org/10.1016/S2468-2667(20)30061-X

16. L.V. Kolpina, I.V. Boyarinova, M.N. Reutova, E.V. Reutov, Theor. Pract. Soc. Devel. 10(152), 23-28 (2020)

17. D. Banerjee, Asian J. Psychiatr. 51, 102154 (2020). https://doi.org/10.1016/j.ajp.2020.102154

18. R.N. Lunkin, Bul. PFUR Univ. Ser.: Polit. 22(4), 547-558 (2020). https://doi.org/10.22363/2313-1438-2020-22-4-547-558 